\title{
Design of a $\mathrm{TE}_{10}$-to- $\mathrm{TE}_{61}$ mode coupler for a 372 $\mathrm{GHz}$ gyrotron travelling wave amplifier
}

\author{
Liang Zhang, Jason Garner, Craig R. Donaldson, Wenlong He, Alan D.R. Phelps and Adrian W. Cross \\ Department of Physics, SUPA, \\ University of Strathclyde \\ Glasgow, Scotland, UK, G4 0NG \\ liang.zhang@strath.ac.uk
}

\begin{abstract}
This paper presents the design of a $\mathrm{TE}_{10}$-to-TE $\mathrm{TE}_{61}$ mode coupler for a $372 \mathrm{GHz}$ gyrotron travelling wave amplifiers. The optimized coupler was able to achieved an $-1 \mathrm{~dB}$ transmission over the frequency band of 359 - 385 GHz. The designed coupler was scaled to W-band for manufacture and measurement. The measured transmission and phase response confirmed the mode coupling between the input $\mathrm{TE}_{10}$ mode and the desired $\mathrm{TE}_{61}$ mode.
\end{abstract}

Keywords-microwave coupler, gyro-amplifiers, waveguide branches, higher order mode.

\section{INTRODUCTION}

Gyrotron traveling wave amplifiers (Gyro-TWAs) are coherent electromagnetic radiation sources based on the cyclotron resonance maser (CRM) instability [1]. They are able to generate high power, broadband, high frequency output up to Terahertz frequency range. They can find applications in plasmas diagnostics, remote sensing, electron spin resonance spectroscopy, and so on.

A W-band gyro-TWA has been developed in university of Strathclyde for cloud profiling radar application. The gyroTWA operates in the frequency range of $90-100 \mathrm{GHz}$. It uses a three-fold helically corrugated waveguide [2, 3] as the interaction region, whose eigen wave was generated by the coupling between $\mathrm{TE}_{21}$ mode and space harmonic $\mathrm{TE}_{11}$ mode in the circular waveguide. A W-band gyrotron backward wave oscillator (gyro-BWO) with similar setup compared to the gyroTWA achieved a maximum output power of $12 \mathrm{~kW}$ when driven by a $40 \mathrm{kV}, 1.5 \mathrm{~A}$, annular-shaped large-orbit electron beam [4]. By tuning the cavity magnetic field strength, the output frequency of the gyro-BWO can be tuned from $88 \mathrm{GHz}$ to $102.5 \mathrm{GHz}$.

A gyro-TWA operates at higher frequency center of 372 $\mathrm{GHz}$ is currently been studied. However, if a three-fold helically corrugated waveguide is still used for the device, the mean radius will become much smaller, around $0.4 \mathrm{~mm}$, which makes the manufactory very difficult. Operating at higher order mode is a possible solution. It can not only increase the dimensions of waveguide structures, but also enhance the power handling capability of the device. A TWA using an high-fold helically corrugated waveguide was proposed. Its radius is nearly doubled when comparing with a 3-fold one for the same operating frequency range. The TWA requires an input mode of $\mathrm{TE}_{61}$ in the circular waveguide, which is not able to directly obtain from the input $\mathrm{TE}_{10}$ mode in rectangular waveguide.

In this paper, the design of a mode coupler that converters from the $\mathrm{TE}_{10}$ mode in rectangular waveguide into the $\mathrm{TE}_{61}$ mode in circular waveguide is presented, and the designed coupler was scaled to W-band for manufacture and measurement. The transmission and phase response were measured and analyzed which confirmed the mode coupling between the input $\mathrm{TE}_{10}$ mode and the desired $\mathrm{TE}_{61}$ mode.

\section{INPUT MODE CONVERTER}

The schematic of the gyro-TWA is shown in Fig. 1. The input seed microwave signal will be coupled in from the sidewall into the device through a pillbox window (4), a waveguide bent, and the coupler (5) [5 - 7], a cusp electron gun (1) [8], the output launcher $[9,10]$, and the microwave window (6) [11, 12].

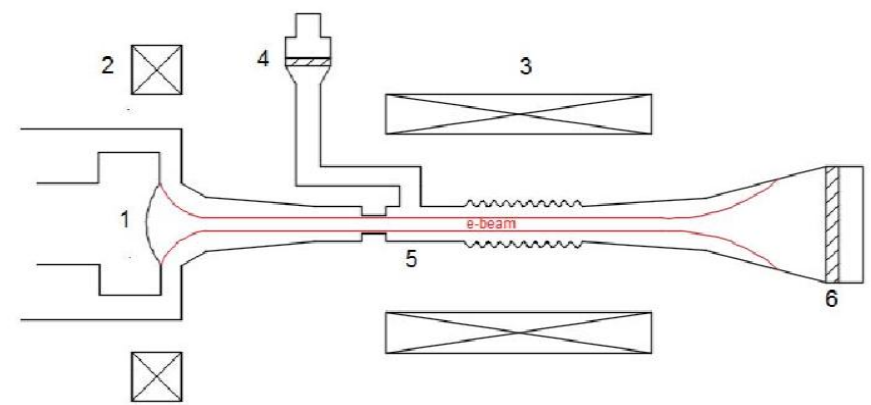

Fig. 1 The schematic of the $372 \mathrm{GHz}$ gyro-TWA.

The design of the mode converter was based on the principal of incident wave power distribution to a high order mode. A few high-order mode converters has been designed in the literature, for example, the $\mathrm{TE}_{13}$ mode, and $\mathrm{TE}_{01}$ modes [13, 14]. From the principle of mode excitation, the possible modes can be excited by different branch numbers is listed in table 1 . In order to excite $\mathrm{TE}_{61}$ mode in the circular waveguide, the branch number has to be 2,3 or 6 . A $\mathrm{TE}_{61}$ mode excited by a 3branch or 6-branch coupler will have better mode purity, however, it introduces additional difficult to match the phase of 
individual branch. Therefore, a mode converter that has two branches was chosen.

Table 1 Waveguide branch number and potential modes.

\begin{tabular}{|c|c|c|}
\hline $\begin{array}{c}\text { Branch } \\
\text { No. }\end{array}$ & $\begin{array}{c}\text { Converting } \\
\text { Mode }\end{array}$ & \multicolumn{1}{c|}{$\begin{array}{c}\text { Cavity } \\
\text { Modes }\end{array}$} \\
\hline 2 & $\mathrm{TE}_{21}$ & $\mathrm{TE}_{21}, \mathrm{TE}_{41}, \mathrm{TE}_{61}, \mathrm{TE}_{81} \ldots$ \\
\hline 3 & $\mathrm{TE}_{31}$ & $\mathrm{TE}_{31}, \mathrm{TE}_{61}, \mathrm{TE}_{91}, \mathrm{TE}_{12,1} \cdots$ \\
\hline 4 & $\mathrm{TE}_{41}$ & $\mathrm{TE}_{41}, \mathrm{TE}_{81}, \mathrm{TE}_{12,1} \cdots$ \\
\hline 5 & $\mathrm{TE}_{51}$ & $\mathrm{TE}_{51}, \mathrm{TE}_{10,1}, \mathrm{TE}_{15,1} \cdots$ \\
\hline 6 & $\mathrm{TE}_{61}$ & $\mathrm{TE}_{61}, \mathrm{TE}_{12,1}, \mathrm{TE}_{18,1} \ldots$ \\
\hline
\end{tabular}

It is of great importance to match the phase between the two branches therefore to achieve good coupling. A tapered waveguide structure was design to provide a smooth impedance match between the waveguide branches. To simplify the complexity of the manufacture process, single Eplane linearly variation was used. In the simulation, the reflection was less than $-25 \mathrm{~dB}$.

The higher order mode converter was designed and optimized by using the simulation package CST microwave studio. To avoid the potential mode exciting of $\mathrm{TE}_{21}$ and $\mathrm{TE}_{41}$, the radius of the circular waveguide was chosen slightly smaller to cut off the undesired $\mathrm{TE}_{41}$ mode. The final structure, as well as the field distribution inside the coupler is shown in Fig. 2. It is clearly shown that the excited mode is $\mathrm{TE}_{61}$.

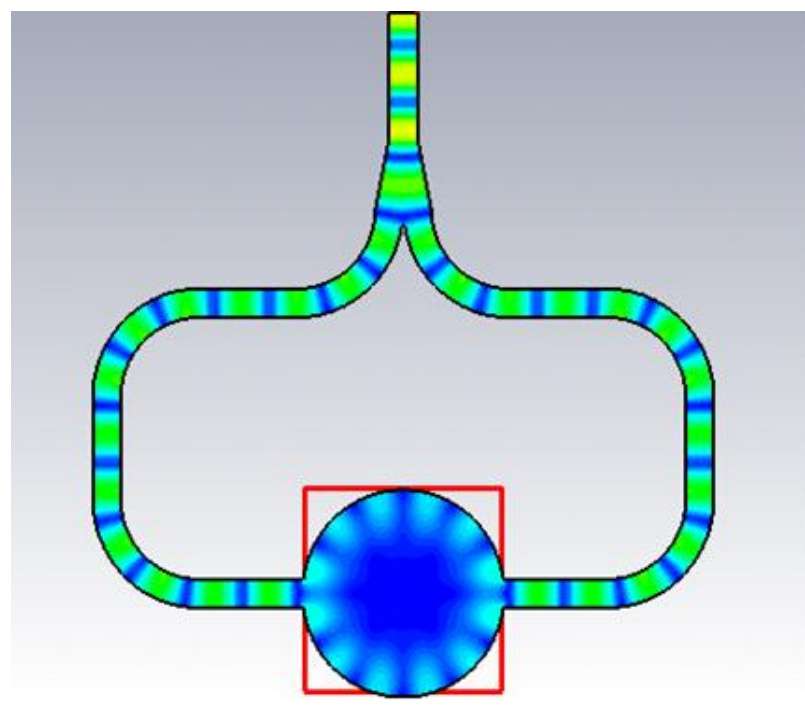

Fig. 2 The field distribution of the waveguide splitter input coupler.

The designed mode coupler was frequency-scaled down to $\mathrm{W}$-band, and a prototype was manufactoried and measured by using a vector network analyzer (VNA). The whole structure was devided into two pieces, and machined by using an inhouse $\mathrm{CNC}$ milling machine individually. Two identical mode couplers were machined in order for the back-to-back measurement. In the measurement, the input $\mathrm{TE}_{10}$ mode in the rectangular waveguide will be convetered into the $\mathrm{TE}_{61}$ mode in the circular waveguide and then convertered back. Fig. 3 shows the drawing of couplers and Fig. 3(b) shows the machined structure on aluminium plates.

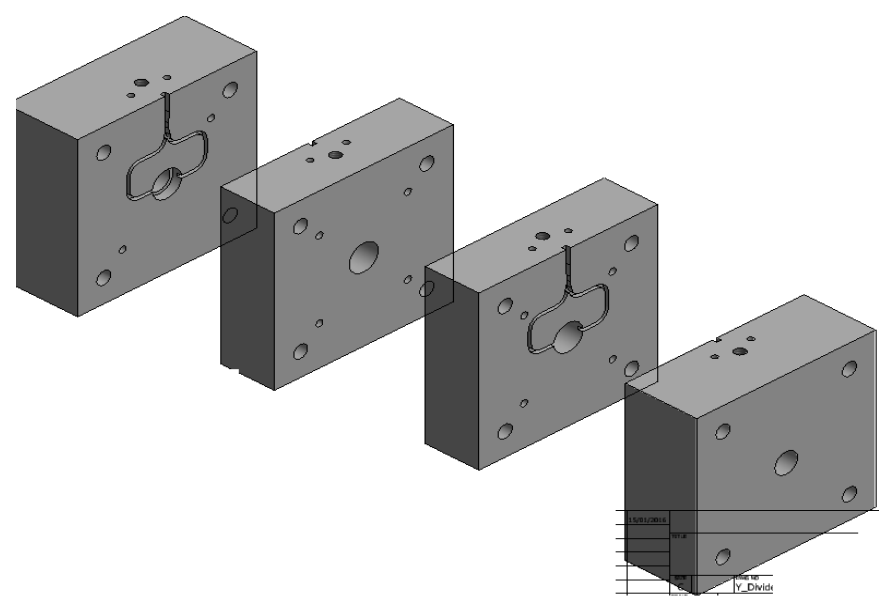

(a)

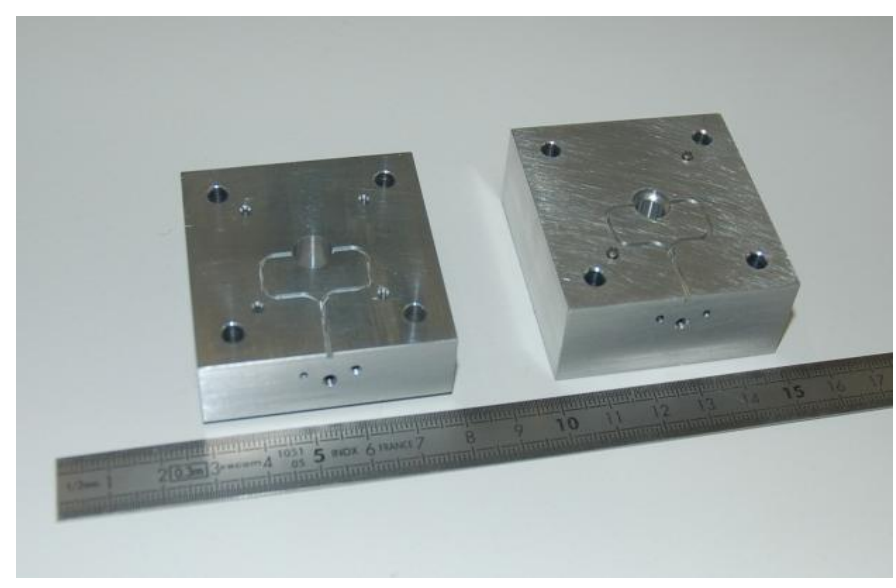

(b)

Fig. 3 The drawing of the mode coupler (a), and manufactured pieces (b).

The microwave properties of the mode coupler was measured by a W-band VNA. The setup is shown in Fig. 4. The transmission of the measured components are shown in Fig. 5. The average loss is about $-2.5 \mathrm{~dB}$ for two identical couplers, which suggests about $90 \%$ of incident microwave signal is transmitted into the circular coupled waveguide.

To verify the mode inside the circular waveguide, an additional smooth waveguide section of length $3.00 \mathrm{~mm}$ was inserted between the two couplers to measure the phase response. It was then compared with the theoretical phase response of the $\mathrm{TE}_{61}$ mode in the same waveguide. It was found that both of phase information agreed well with each other. 


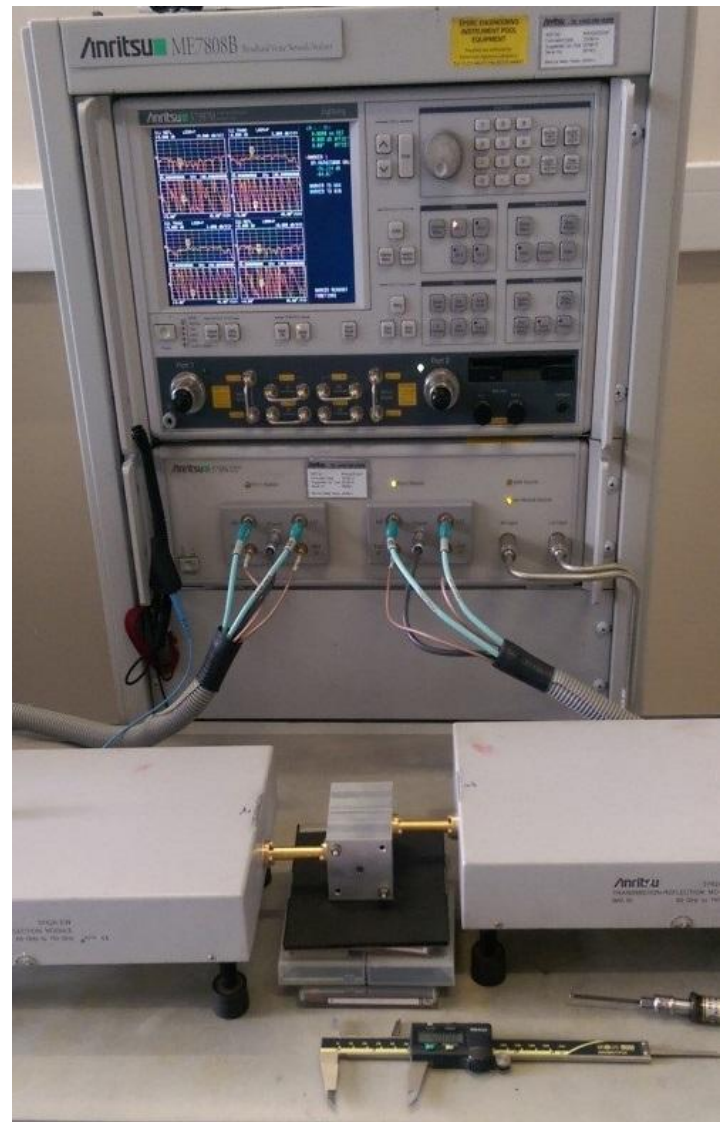

Fig. 4 Measurement setup of the higher order mode coupler.

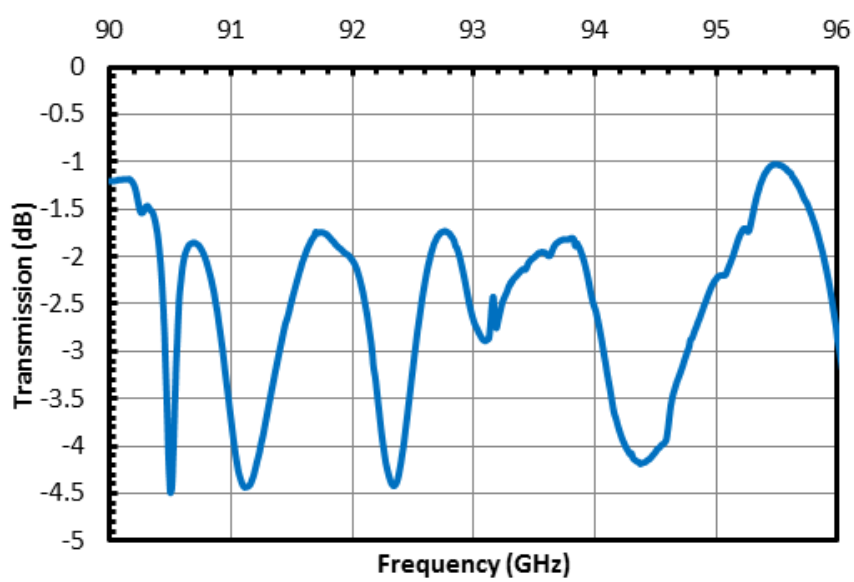

Fig. 5 Measured transmission of W-band high order mode coupler.
This work was supported by the Engineering and Physical Sciences Research Council (EPSRC) U.K. under Research Grants EP/M008622/1, EP/K029746/1.

\section{REFERENCES}

[1] K. R. Chu, "The electron cyclotron maser," Rev. Mod. Phys. vol. 76, no. 2, pp. 489-540, 2004.

[2] L. Zhang, W. He, K. Ronald, A. D. R. Phelps, C. G. Whyte, C. W. Robertson, A. R. Young, C. R. Donaldson and A. W. Cross, "Multimode Coupling Wave Theory for Helically Corrugated Waveguide," IEEE Trans. Microw. Theory Techn., vol. 60, no. 1, pp. 1-7, 2012.

[3] V. L. Bratman, A. W. Cross, G. G. Denisov, W. He, A. D. R. Phelps, K. Ronald, S. V. Samsonov, C. G. Whyte, and A. R. Young, "High-gain wide-band gyrotron traveling wave amplifier with a helically corrugated waveguide," Phys. Rev. Lett., vol. 84, no. 12, pp. 2746-2749, Mar. 2000.

[4] W. He, C. R. Donaldson, L. Zhang, K. Ronald, P. McElhinney, and A.W. Cross, "High power wideband gyrotron backward wave oscillator operating towards the terahertz region," Phys. Rev. Lett., vol. 110, no. 16, p. 165101, 2013.

[5] J. R. Garner, L. Zhang, C. R. Donaldson, A. W. Cross, and W. He, "Design Study of a 372-GHz High Order Mode Input Coupler," IEEE Trans. Electron Devices, vol. 63, no. 8, pp. 3284-3290, Aug. 2016.

[6] J. R. Garner, L. Zhang, C. R. Donaldson, A. W. Cross, and W. He, "Design Study of a Fundamental Mode Input Coupler for a 372-GHz Gyro-TWA I: Rectangular-to-Circular Coupling Methods," IEEE Trans. Electron Devices, Vol. 63, no. 1, pp. 497-503, 2016.

[7] L. Zhang, W. He, C. R. Donaldson, J. R. Garner, P. McElhinney, and A. W. Cross, "Design and measurement of a broadband sidewall coupler for a W-band gyro-TWA," IEEE Trans. Microw. Theory Techn., Vol. 63, no. 10 , pp. 3183-3190, 2015.

[8] C. R. Donaldson, W. He, A. W. Cross, F. Li, A. D. R. Phelps, L. Zhang, K. Ronald, C. W. Robertson, C. G. Whyte, and A. R. Young, "A cusp electron gun for millimeter wave gyrodevices," Appl. Phys. Lett., vol. 96, no. 14 , p. 141501, 2010.

[9] P. McElhinney, C. R. Donaldson, L. Zhang, and W. He, "A high directivity broadband corrugated horn for W-band gyro-devices," IEEE Trans. Antennas Propag., vol. 61, no. 3, pp. 1453-1456, 2013.

[10] P. McElhinney, C.R. Donaldson, J. E. McKay, L. Zhang, D. A. Robertson, R. I. Hunter, G. M. Smith, W. He, and A.W. Cross, "An output coupler for a W-band high power wideband gyro-amplifier," IEEE Trans. Electron Devices, 64, no. 1, accepted, 2017.

[11] C. R. Donaldson, W. He, L. Zhang, and A. W. Cross, "A W-band multilayer microwave window for pulsed operation of gyro-devices," IEEE Microw. Wireless Compon. Lett., vol. 23, no. 5, pp. 237-239, 2013.

[12] C. R. Donaldson, P. McElhinney, L. Zhang, and W. He, "Wide-band HE11 mode terahertz wave windows for gyro-amplifiers," IEEE Trans. THz Sci. Technol., Vol. 6, no. 1, pp. 108-112, 2016.

[13] C. F. Yu and T. H. Chang, "High-performance circular TE $\mathrm{TE}_{01}$-mode converter," IEEE Trans. THz Sci. Technol., vol. 53, no. 12, pp. 37943798, 2005.

[14] G. Liu, R. Yan, Y. Luo, and S. Wang, "A $\mathrm{TE}_{13}$ mode converter for highorder mode gyrotron-traveling-wave tubes," IEEE Trans. Electron Devices, vol. 63, no. 1, pp. 486-490, Jan. 2016. 